\title{
49. On the Separation of Glycerides.
}

\author{
Part IV. Oil of Silkworm Pupa.
}

By Bunsuke Suzuki and Yoshikuni Yokoyama.

Bíochemical Laboratory, Faculty of Agriculture, Kyoto Imperial University.

(Rec. April 9, 1928. Comm. by U. SUzukI, M.I.A., April 12, 1928.)

The fatty acid constuents of the oil of the silkworm pupa were studied by Tsujimoto, ${ }^{1)}$ Kobayashi, ${ }^{2)}$ Kawase, ${ }^{3)}$ Kato ${ }^{4)}$ and Kimura. ${ }^{\text {) }}$ The results of these studies differ more or less according to the investigators, but accepting the combined results, the oil seems to consist of glycerides of palmitic, oleic, isolinoleic and linolenic acids. The aim of this study was to see in what combinations these acids do exist in the oil as glycerides. The procedures adopted to attain the object were similar, in general outline, to those in the cases of the oils which were presented in previous papers. In previous cases, however, brominated oil soluble in petroleum ether was left untreated. This portion of brominated oils is soluble in most of the ordinary organic solvents so that suitable solvents to effect the separation of glycerides could not be found. This separation, however, was attained in the present study, by using alcoholic solutions of calcium chloride of various concentrations. The outline of the procedures as well as the glycerides separated are shown in the following tables.

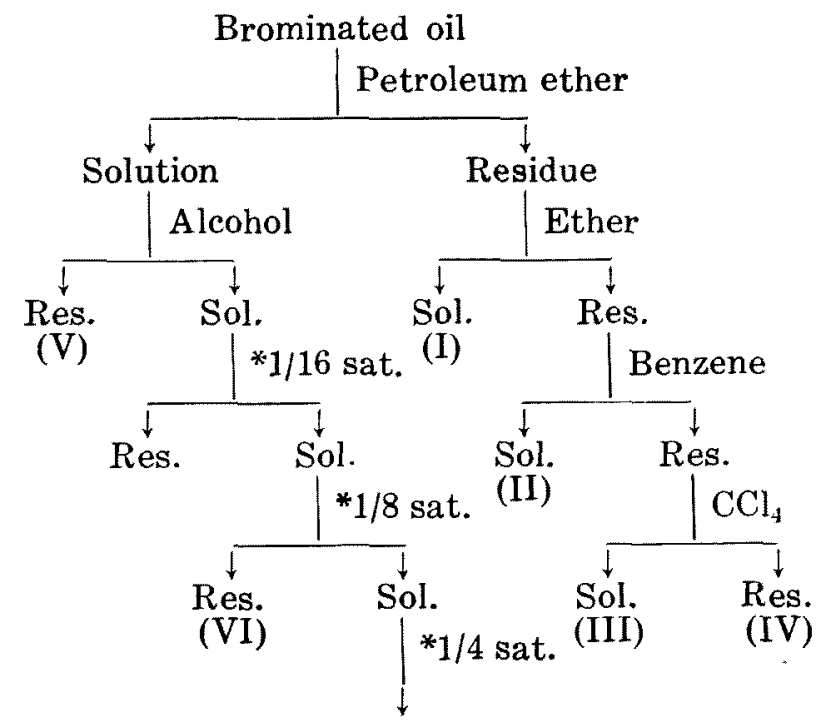

1) Tsujimoto, J. Soc. Chem. Ind. Japan, 17 (1914), 1388.

2) Kobayashi, ibid. 21 (1918), 321.

3) Kawase, J. Chem. Soc. Japan, 42 (1921), 181.

4) Kato, J. Agr. Chem. Soc. Japan, 1 (1924), 679.

5) Kimura, J. Soc. Chem. Ind. Japan, 30 (1927), 858. 


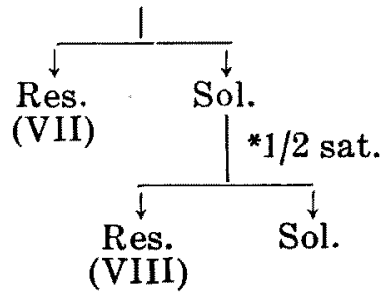

* Saturated alcoholic solution of calcium chloride

M.p.

1. Dioleo-linolenin bromide

$86^{\circ} \mathrm{C}$.

2. Isolinoleo-dilinolenin bromide*

$133^{\circ}$

3. Isolinoleo-dilinolenin bromide*

$154^{\circ}$

4. Trilinolenin bromide

$172^{\circ}$

5. Triolein bromide**

oil

6. Palmito-oleo-linolenin bromide

7. Triolein bromide**

8. Palmito-diolein bromide

* Isomeric to each other

** The same substance

It is not claimed that our process of separation is quantitative. However if we consider the total yield of crude bromo-glycerides it corresponds to $83 \%$ of the oil used, the content of triolein being more than half the amount.

\section{EXPERIMENTAL}

1. Dioleo-linolenin bromide. Soluble in ether but with difficulty soluble in petroleum ether. Purified by repeated precipitation from ether. M.p.: $86^{\circ} \mathrm{C}$., $\mathrm{Br}: 47.09 \%$ (calc. 47.56). The glyceride was hydrolysed with $\mathrm{HCl}$ and hexabromostearic acid (m.p.: $178^{\circ} \mathrm{C}, \mathrm{Br}$ : $63.03 \%$ (calc. 63.32 ) ) and dibromostearic acid (an oil, $\mathrm{Br}: 36.51 \%$ (calc. (36.18) ) were obtained in molar proportion of $1.00: 2.08$.

2. Isolinoleo-dilinolenin bromide. Obtained by treating the residue of (1) with benzene. Purified by precipitating several times from the solvent. M.p. : $133^{\circ} \mathrm{C}$., $\mathrm{Br}: 59.11 \%$ (calc. 59.37 ). On hydrolysing the glyceride with $\mathrm{HCl}$, hexabromostearic acid (m.p. : $178^{\circ} \mathrm{C}$., $\mathrm{Br}: 63.73 \%$ ) and isolinoleic acid tetrabromide (an oil, $\mathrm{Br}: 53.79 \%$ (calc. 53.33)) were obtained in molar proportion of $2.20: 1.00$.

3. Isolinoleo-dilinolenin bromide. The residue of (2) was treated with $\mathrm{CCl}_{4}$, a part having removed into the solution, which was purified by reprecipitating repeatedly from the same solvent. On hydrolysing the glyceride with $\mathrm{HCl}$, hexabromostearic acid (m.p.: $178^{\circ} \mathrm{C}$., Br. : $63.83 \%$ ) and isolinoleic acid tetra bromide (an oil, Br. : $52.86 \%$ ) were obtained in molar proportion of $1.85: 1.00$. 
4. Trilinolenin bromide. The final residue from the above treatments was soluble in hot benzene from which it crystallized out when cooled. M.p. : $172^{\circ} \mathrm{C}$., $\mathrm{Br}: 62.03 \%$ (calc. 62.23 ). The glyceride is identical with that obtained from soy bean oil (m.p.: $166^{\circ} \mathrm{C}$ ). The m.p. of both samples differ somewhat, but in this case we were able to have on hand a large amount (262g) of the material enabling us to purify at will so that we take $172^{\circ} \mathrm{C}$. as correct. On hydrolysing the glyceride with $\mathrm{HCl}$, hexabromostearic acid (m.p. : $178^{\circ} \mathrm{C} ., \mathrm{Br}: 63.17 \%$ ) and no other acid was obtained.

5. Triolein bromide. To a petroleum ether solution of brominated oil, alcohol was added, when two layers separated out. The upper ethereal solution was taken, evaporated to dryness, and the residue washed thouroughly with alcohol until $\mathrm{Br}$-content remained constant. It was an oil which solidifies at about $3^{\circ} \mathrm{C}$. $\mathrm{Br}: 35.62 \%$ (calc. 35.14 ). On hydrolysing the glyceride with $\mathrm{HCl}$, dibromostearic acid (an oil, $\mathrm{Br}: 36.56 \%)$ to the amount of $90.5 \%$ of the theory and no other acid was obtained.

6. Palmito-oleo-linolenin bromide. The liquid part of the brominated glycerides which was soluble in alcohol was treated with a 1/16 saturated alcoholic solution of $\mathrm{CaCl}_{2}$ when some precipitates were obtained but the quantity was so small that it did not allow of further study. The fraction which was soluble in the solvent was treated with a 1/8 saturated solution and an oil, which was with difficulty soluble in the latter solvent, was obtained. $\mathrm{Br}: 43.01 \%$ (calc. 43.16.) The glyceride was hydrolysed with $\mathrm{HCl}$ and the resultant acids were separated into 3 fractions, by using petroleum ether. Hexabromostearic acid (m.p. : $\left.178^{\circ} \mathrm{C} ., \mathrm{Br}: 63.80 \%\right)$ remained insoluble in the solvent while dibromostearic acid (an oil, $\mathrm{Br}: 36.54 \%$ ) and palmitic acid (m.p.: $62^{\circ} \mathrm{C}$., $\mathrm{C}: 74.54 \%$ (calc. 74.93 ), $\mathrm{H}: 12.28 \%$ (calc. 12.59) ) went into solution from which palmitic acid crystallized out when cooled. The molar proportions of the three acids were $1.00: 1.25: 1.34$.

7. Triolein bromide. The portion, soluble in a $1 / 8$ saturated alcoholic solution of $\mathrm{CaCl}_{2}$, was treated, in its turn, with a $1 / 4$ saturated solution and again an oil, which solidifies at about $3^{\circ} \mathrm{C}$, and which contains $\mathrm{Br}$ to the extent of $34.84 \%$, separated out. On hydrolysing the glyceride with $\mathrm{HCl}$, dibromostearic acid (an oil, $\mathrm{Br}: 36.02 \%$ ), to the amount of $91.4 \%$ of the theory, and no other acid was obtained.

8. Palmito-diolein bromide. The alcoholic (1/4 saturated with $\mathrm{CaCl}_{2}$ ) solution of the glycerides were treated with a $1 / 2$ saturated solution thus dividing the glycerides into two fractions; i.e. one which is easily and the other with difficulty soluble in the solvent, but the 
latter fraction was so small in quantity that its further study could not be carried out. The former fraction consisted of the glyceride which is an oil and solidifies at about $5^{\circ} \mathrm{C}$. and contains $\mathrm{Br}$ to the extent of $26.52 \%$ (calc. 27.12). On hydrolysing the glyceride with $\mathrm{HCl}$, dibromostearic acid (an oil, $\mathrm{Br}: 36.68 \%$ ) and palmitic acid (m.p. : $62^{\circ} \mathrm{C}$., C : $74.44 \%, \mathrm{H}: 12.53 \%$ ) were obtained in molar proportion of $2.32: 1.00$.

Our sincere thanks are due to the Department of Education, Imperial Government, which provided a part of the expense of this study. 